\title{
云南新平哀牢山夜间捕获鸟类的多样性
}

\author{
杨 婷 ${ }^{1,2}$, 王紫江 ${ }^{3}$, 刘鲁明 ${ }^{1}$, 杨晓君 ${ }^{1, ~ *}$, 安庆媛 ${ }^{3}$, 张宏雨 ${ }^{4}$, 杨显明 ${ }^{4}$, 鲁发旺 ${ }^{4}$ \\ (1. 中国科学院昆明动物研究所, 云南 昆明 650223 ; 2. 中国科学院研究生院, 北京 100049 ; 3. 昆明鸟类协会, 云南 昆明 650021 ; \\ 4. 哀牢山国家级自然保护区新平管理局, 云南 新平 653400)
}

\begin{abstract}
摘要: 2007-09-05-2007-11-05 和 2008-09-03-2008-11-07 期间, 在云南省新平县哀牢山金山Ү口用灯光诱捕 对秋季夜间迁徙鸟类组成进行了调查。共捕获鸟类 129 种, 7943 只, 分属于 14 目 23 科。雀形目鸟类为网捕主要 鸟类, 占总网捕数量的 $58.9 \%$ 。其中红尾伯劳(Lanius cristatus)、小杜鹃(Cuculus poliocephalus)和红喉歌鸲(Luscinia calliope 3 种是该地夜间网捕优势种鸟类，三者数量皆超过网捕鸟类总数的 5\%。每天夜间 20:00-22:00 和次日凌 晨 04:00-06:00 是捕获鸟类数量的高峰时段。网捕期间, 早期 Shannon-Wiener 指数和 Pielou 指数最低, 优势指数 $\mathrm{C}$ 最高; 中期 Shannon-Wiener 指数和 Pielou 指数最高, 优势度指数 C 最低。2008 与 2007 年相比, 优势指数 C 和 G-F 指数较低, 但 Shannon-Wiener 指数和 Pielou 指数较高。云南省不同“打雀山”夜间捕获鸟类的种类和数量存在 差异。地理和气候可能是造成这些差异的主要因素。
\end{abstract}

关键词: 哀牢山; 金山Ү口; 夜间网捕鸟类; 多样性

中图分类号：Q959.7 文献标识码：A 文章编号：0254-5853-(2009)03-0303-08

\section{Diversity of the Birds Captured at Night in Ailao Mountain, Xinping County, Yunnan Province}

\author{
YANG Ting ${ }^{1,2}$, WANG Zi-jiang ${ }^{3}$, LIU Lu-ming ${ }^{1}$, YANG Xiao-jun ${ }^{1, *}$, AN Qing-yuan ${ }^{3}$, \\ ZHANG Hong-yu ${ }^{4}$, YANG Xian-ming ${ }^{4}$, LU Fa-wang ${ }^{4}$ \\ (1. Kunming Institute of Zoology, the Chinese Academy of Sciences, Kunming Yunnan 650223, China; 2. Graduate University of \\ the Chinese Academy of Sciences, Beijing 100049, China; 3. Kunming Birds Conservation Association, Kunming Yunnan \\ 650021, China; 4. Xinping Bureau of Yunnan Ailao Mountains National Reserves, Xinping Yunnan 653400, China)
}

\begin{abstract}
The composition of nocturnal migratory birds was investigated by light trapping at Jinshan yakou in Ailao Mountain, Xinping County, Yunnan Province from September 5th to November 5th 2007 and from September 3rd to November 7th 2008. Totally, 7943 individuals of 129 species, which belong to 23 families, 14 orders, were caught. Passerines were the main species at $58.9 \%$ of all birds captured. Lanius cristatus, Cuculus poliocephalus, Luscinia calliope were predominant and every one was more than 5\%. The number of birds captured was highest from 20:00 to 22:00 and from 04:00 to 06:00 every day. During 2007 and 2008, Both of Shannon-Wiener diversity index and Pielou evenness index were lowest, and $\mathrm{C}$ index was highest in early period. However, both of the Shannon-Wiener diversity index and Pielou evenness index were highest, and $\mathrm{C}$ index was lowest in the middle stage. $\mathrm{C}$ index and G-F index were higher in 2007 than in 2008. But Shannon-Wiener diversity index and Pielou evenness index were higher in 2008 than in 2007. There were differences with the number and species of the birds captured at night between various birds migration localities. Geography and climate were important factors that affect the differences.
\end{abstract}

Key words: Ailao Mountain; Jinshan yakou; Birds captured at night; Diversity

候鸟迁徙分昼间迁徙、夜间迁徙和昼夜迁徙等 不同类型（Zhang \&Yang, 1997)。大多数陆地鸟类 是在夜间迁徙, 几乎所有的猛禽都是白天迁徙, 水
鸟昼间和夜间迁徙的都有（Zheng，1995; Zhang \& Yang，1997）。夜间网捕鸟类主要针对的是夜间迁 徙鸟。对路经某地的夜间迁徙鸟类组成的调查, 不 
但可以了解候鸟迁徙规律, 如迁徙的群集情况、迁 徙高峰时间、迁徙路径和方向、迁徙与天气、地形 等的关系等 (Zheng，1995; Zhang \& Yang，1997); 也将有助于进一步了解这个地方的生物多样性, 为 制定科学的保护和管理办法提供详细的科学资料。

在较多地方都进行过夜间迁徙鸟类的调查研 究, 如1995年的以色列南部 (Bruderer \& Liechti, 1995 )；1999年的美国德克萨斯州（William \& David，1999)；2001年的瑞典南部 (Susanna et al, 2001 )；2004年的俄勒冈州东北部和华盛顿州东南 部（Todd \& Brian，2004）等。在中国夜间迁徙岛 类的调查主要集中在各“打雀山”, 而“打雀山”是鸟 类在迁徙过程由宽面迁徙向狭面迁徙形成的特殊 自然现象（Tang et al，2003）, 它主要分布于在我 国的西南和南方少数地区, 云南 ( Wu \& $\mathrm{Li}, 1999$ )、 广西 (Jiang et al，2006)、湖南 ( Tang et al, 2003) 以及江西等 (Xiao et al, 2005)。云南各种类型的“打 雀山”共16个（Wu \& Li，1999; Wang et al，2006）, 但对此进行过调查研究的有大理巍山 (Chu et al, 1998; Yang et al, 2004)、南涧风凰山 (Huang et al, 2006; Han et al, 2007)、新平者竜(Wei et al, 1983)。

在云南新平哀牢山，2004年、2005年和2006 年曾对夜间网捕鸟类的种类和数量进行过统计 (Zhang，2009; Wang \& Zhao，2009)，3年环志岛 类共179种, 其中雀形目鸟类 117 种占 $65.3 \%$, 非雀 形目鸟类 62 种占 $34.7 \%$, 其中数量排在前五位的有 红尾伯劳 (Lanius cristatus), 厚嘴苇莺 (Acrocephalus aedon), 红喉歌鸲 (Luscinia calliope), 小杜鹃 (Cuculus poliocephalus), 池鹭 (Ardeola bacchus) (Zhang, 2009)。并未对该地的夜间网捕鸟类组成 以及多样性进行更详细的分析。为了进一步科学 地、定量地了解哀牢山金山Y口夜间网捕鸟类组 成, 笔者于 2007年和2008年的9-11月在云南省玉 溪市新平县哀牢山金山Y口对夜间迁徙鸟类的组 成进行了调查, 现将有关结果报道如下。

\section{1 研究地点与方法}

\section{1 研究地点}

哀牢山海拔 2 080-3165.9m, 纵贯云南中部, 呈西北一东南走向, 在行政上分别隶属于楚雄、双 柏、新平、景东、镇沅五县所辖。其地理位置在东 经 $100^{\circ} 54^{\prime}$, 北纬 $23^{\circ} 36^{\prime}-24^{\circ} 44^{\prime}$ (Liu et al, 1988)。 哀牢山以东是滇中高原面, 元江河谷地槽构成一条
西北一东南的通道; 以西是高山峡谷相间的横断山 脉。来自北方的迁徙鸟, 受到哀牢山的阻挡, 就沿 山脉东侧的地槽向东南飞行。哀牢山秋季的雾气, 对秋季南迁的小型候鸟有一定的阻挡和截留作用

(Wei et al，1983; Wei et al，1988）。

金山Y口地处哀牢山中段, 位于玉溪市新平县 和普洱市镇源县的交界处, 是哀牢山沿山脊方向上 两个山峰间呈马鞍状的明显下凹处，因地处金山而 得名。地理坐标为东经 $101^{\circ} 30^{\prime}$, 北纬 $23^{\circ} 57^{\prime}$ 。海拔 在 2180-2360 $\mathrm{m}$ 之间（图 1）。属中亚热带半湿润 高原季风气候类型, 年平均气温 $16.4^{\circ} \mathrm{C}$ 。冬夏季分 别受两种不同的大气候环流影响, 冬季 (11 月到次 年 4 月), 受来自阿拉伯沙漠和印度洋北部大陆上 空干暖气候控制，空气干暖、降水少、晴天多、日 照充足、昼夜温差大。夏季 (5 月到 10 月) 受印度 洋和太平洋暖湿气流的控制, 空气湿度大、降雨多, 日照较少、昼夜温差小, 多雾 (Zhang, 2009)。

\section{2 研究方法}

1.2.1 调查方法 野外调查时间为 2007 年 9 月 5 日-11月 5 日和 2008 年 9 月 3 日-11 月 7 日, 共 117 天。每晚 20:00 至次日 06:00, 利用 4 张 ATX (孔 径: $36 \mathrm{~mm}$, 长: $12 \mathrm{~m}$, 高: $2.6 \mathrm{~m}$, 兜数: 5) 专用 捕鸟雾网和 4 台 $300 \mathrm{~W}$ 的白炽灯进行灯光诱捕, 鸟 类上网后, 随即解下并装于专用鸟袋里, 次日进行 种类鉴定和环志, 完成后即刻释放。若网捕数量较 多即在当晚进行鉴定和环志, 并在原地立即释放。 从晚上 20:00 开始, 每隔 2 小时统计一次该时间段 内的网捕种类和数量。

\subsection{2 数据分析 所有数据均输入计算机中进行} 统计分析。本文将整个工作时期平均分为早期 (9 月3日一9月24日)、中期（9月25日-10月16日）、 晚期（10月17日-11月8日）三个时期。夜间网捕 鸟类时间分为 5 个时段, 分别为 20:00-22:00, 22:00-24:00，24:00-02:00，02:00-04:00， 04:00-06:00。分别采用Shannon-Wiener指数、Pielou 指数和优势指数 $\mathrm{C}$ 计算多样性、均匀度和优势度指 标。用G-F指数（Jiang \& Ji，1999）计算科和属间 的多样性。用非参数多个独立样本检验

（K-Independent samples Test）检验2007年和2008 年各时期种类和数量的差异性。应用单因素方差分 析(One-way ANOVA)分析 2008 年各时段种类和数 量是否有差异。所有数据分析全部在SPSS 13.0软件 中进行。 


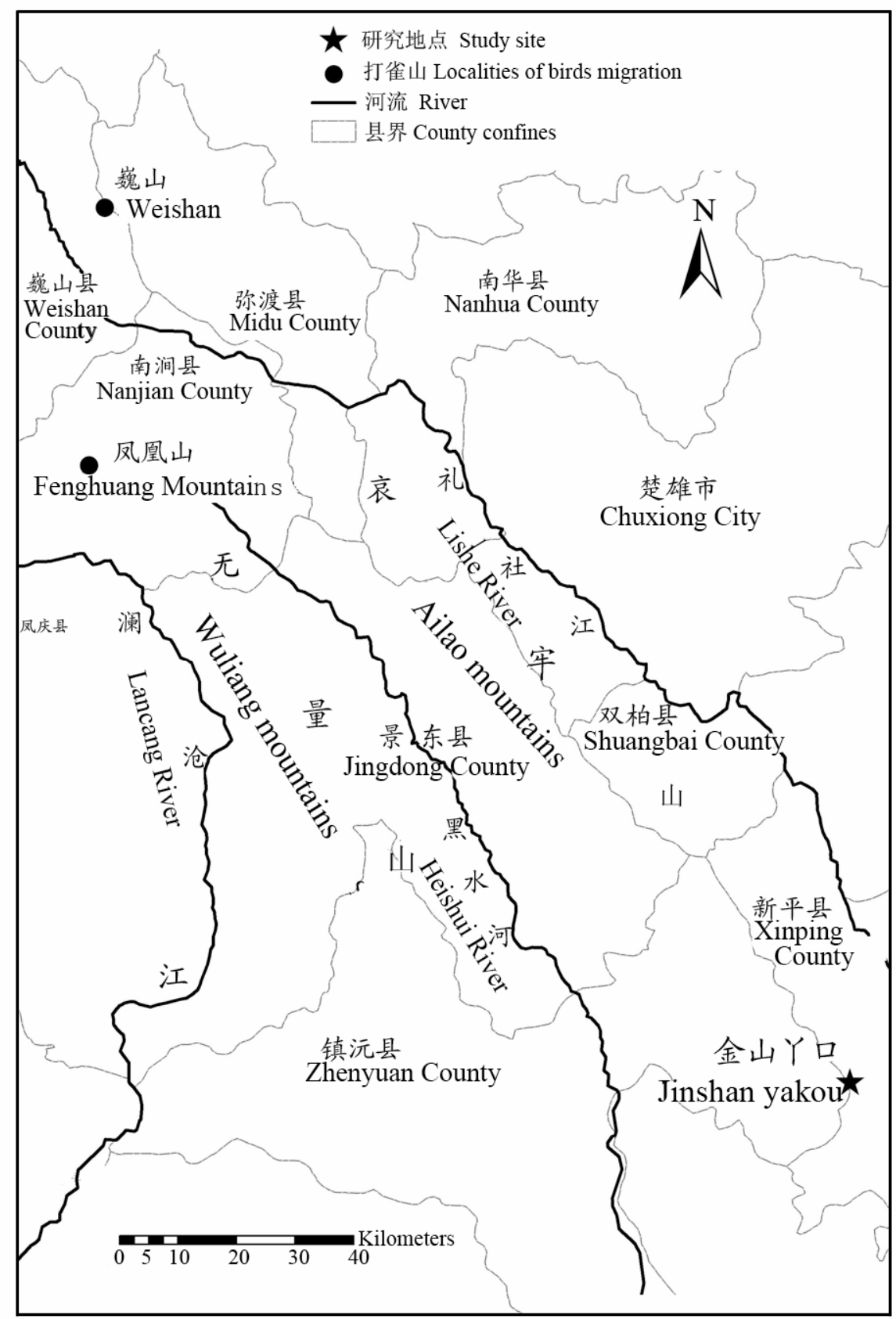

图 1 云南省新平县哀牢山金山Y口夜间网捕鸟类地点示意图

Fig. 1 Location of capturing birds by net at night at Jinshan yakou of Ailao Mountain, Xinping County, Yunnan Province

\section{2 结 果}

\section{1 鸟类组成}

哀牢山金山Y口鸟类环志监测点 2 年共在夜间 网捕鸟类 129 种, 7943 只, 分属于 14 目 23 科 (另 4 亚科)。其中雀形目鸟类 76 种，5666 只; 非雀形 目鸟类 51 种, 2277 只。鸟类数量超过捕获量 $1 \%$ 的种类有 14 种 6529 只, 占总数量的 $82.20 \%$; 其中
个体数量居前 3 位的分别为红尾伯劳 (Lanius cristatus) (3642 只, 占 45.85\%)、小杜鹃(Cuculus poliocephalus)（494 只，占 $6.22 \%$ ）和红喉歌鸲 (Luscinia calliope) (406 只, 占 5.11\%), 共计 4542 只, 占总量的 $57.18 \%$ (表 1)。

\section{2 两年鸟类组成变化}

2007 年夜间网捕鸟类 114 种 5529 只, 分属于 14 目 23 科(另 4 亚科), 其中雀形目鸟类 68 种 4140 
只, 非雀形目鸟类 47 种 1389 只。 2008 年夜间网捕 鸟类 97 种 2414 只, 分属 12 目 20 科 (另 4 亚科), 其中雀形目鸟类 58 种 1526 只, 非雀形目鸟类 39 种 888 只。2008 年网捕鸟类较 2007 年新增 15 个种,
未捕到的有 32 种。

2008 年多样性指数, 均匀度指数, 属间多样性 指数都较 2007 年高; 而优势度和科间多样性指数 以及 $G-F$ 指数都较 2007 年低（表 2)。

表 12007 年与 2008 年哀牢山金山Ү口夜间网捕鸟类优势种数量及其百分比

Tab. 1 Amount and percent of dominant bird species captured at night at Jinshan yakou of Ailao Mountain during 2007 and 2008

\begin{tabular}{|c|c|c|c|c|c|c|}
\hline \multirow{3}{*}{ 优势种 Dominant species } & \multicolumn{2}{|c|}{2007 年 } & \multicolumn{2}{|c|}{2008 年 } & \multicolumn{2}{|c|}{ 合计 Total } \\
\hline & 数量 & 百分比 & 数量 & 百分比 & 数量 & 百分比 \\
\hline & No. & Percent $(\%)$ & No. & Percent $(\%)$ & No. & Percent $(\%)$ \\
\hline 红尾伯劳 Lanius cristatus & 2993 & 54.13 & 649 & 26.88 & 3642 & 45.85 \\
\hline 小杜鹃 Cuculus poliocephalus & 322 & 5.82 & 172 & 7.13 & 494 & 6.22 \\
\hline 红喉歌鸲 Luscinia calliope & 144 & 2.60 & 262 & 10.85 & 406 & 5.11 \\
\hline 厚嘴苇莺 Acrocephalus aedon & 253 & 4.58 & 141 & 5.84 & 394 & 4.96 \\
\hline 大杜鹃 Cuculus canorus & 257 & 4.65 & 82 & 3.40 & 339 & 4.27 \\
\hline 池路 Ardeola bacchus & 155 & 2.80 & 122 & 5.05 & 277 & 3.49 \\
\hline 蓝歌鸲 Luscinia cyane & 53 & 0.96 & 105 & 4.35 & 158 & 1.99 \\
\hline 黑胸冻 Turdus dissimilis & 69 & 1.24 & 73 & 3.02 & 142 & 1.79 \\
\hline 红角鸮 Otus scops & 39 & 0.71 & 97 & 4.02 & 136 & 1.71 \\
\hline 黄脚三趾敦 Turnix tanki & 79 & 1.43 & 47 & 1.95 & 126 & 1.59 \\
\hline 鹰鹃 Cuculus sparverioides & 73 & 1.32 & 52 & 2.15 & 125 & 1.57 \\
\hline 灰林即鸟 Saxicola ferrea & 101 & 1.83 & 12 & 0.49 & 113 & 1.42 \\
\hline 山蓝仙鹟 Niltava banyumas & 74 & 1.33 & 18 & 0.75 & 92 & 1.16 \\
\hline 红胸田鸡 Porzana fusca & 55 & 0.99 & 30 & 1.24 & 85 & 1.07 \\
\hline
\end{tabular}

表 22007 年与 2008 年秋季哀牢山金山Ү口夜间网捕鸟类多样性测度指数

Tab. 2 Diversity index of birds captured at night at Jinshan yakou of Ailao Mountain during autumn 2007 and 2008

\begin{tabular}{ccccccccc}
\hline $\begin{array}{c}\text { 年份 } \\
\text { Years }\end{array}$ & $\begin{array}{c}\text { 数量 } \\
\text { No. }\end{array}$ & $\begin{array}{c}\text { 种类 } \\
\text { Species }\end{array}$ & $\begin{array}{c}\text { 多样性 } \\
\text { 指数 } H^{\prime}\end{array}$ & $\begin{array}{c}\text { 均匀度 } \\
\text { 指数 } J\end{array}$ & $\begin{array}{c}\text { 优势度 } \\
\text { 指数 } C\end{array}$ & $\begin{array}{c}\text { 属间多样 } \\
\text { 性指数 } G\end{array}$ & $\begin{array}{c}\text { 科间多样 } \\
\text { 性指数 } F\end{array}$ & $\begin{array}{c}G-F \\
\text { 指数 }\end{array}$ \\
\hline 2007 & 5529 & 114 & 2.30976 & 0.48768 & 0.30413 & 2.03478 & 8.35691 & 0.75652 \\
2008 & 2414 & 97 & 3.06340 & 0.66964 & 0.10344 & 2.71890 & 6.70535 & 0.40548 \\
合计 Total & 7943 & 129 & 2.60989 & 0.29063 & 0.22503 & 2.49942 & 8.72891 & 0.71366 \\
\hline
\end{tabular}

\section{3 多样性随时期变化}

数据结果显示, 早、中、晚期的网捕鸟类平均 数量和种类相差较大 (表 3), 但非参数多个独立样 本检验（K-Independent samples Test）表明: 各期种 类和数量的差异并不显著 $\left(\chi^{2}=0.200-0.344\right.$, $P=0.852-0.905) 。 2$ 年期间早期多样性指数和均匀 度指数最低, 优势度最高; 中期多样性指数和均匀 度指数最高, 优势度最低 (表 4)。
观察数据表明早期开始迁徙的鸟类包括夜鹭 (Nycticorax nycticorax)、山绡鸰 (Dendronanthus indicus)、蓝矶东(Monticola solitarius)、厚嘴苇茑 (Acrocephalus aedon)、栗苇鳽 (Ixobrychus cinnamomeus)、红喉[姬]鈢(Ficedula parva)、鹰鹃 (Cuculus sparverioides); 早期数量达到高峰的鸟类 主要是大杜鹃 (Cuculus canorus)、小杜鹃、红尾伯 劳。中期开始迁飞的鸟类有红角鸮(Otus scops)、红

表 32007 年和 2008 年哀牢山秋季夜间各个时期网捕平均数量和种类

Tab. 3 Number and species of birds captured at night at Jinshan yakou of Ailao Mountain in every stage during autumn 2007 and 2008

\begin{tabular}{|c|c|c|c|c|c|c|c|c|}
\hline \multirow[b]{2}{*}{ 时期 Stage } & \multicolumn{3}{|c|}{2007 年 } & \multicolumn{3}{|c|}{2008 年 } & \multicolumn{2}{|c|}{ 合计 Total } \\
\hline & $\begin{array}{l}\text { 天数 } \\
\text { Days }\end{array}$ & $\begin{array}{c}\text { 平均数 } \\
\text { 量 (只) } \\
\text { Means (ind.) }\end{array}$ & $\begin{array}{c}\text { 种类 (种) } \\
\text { Species } \\
\text { (Species) }\end{array}$ & $\begin{array}{l}\text { 天数 } \\
\text { Days }\end{array}$ & $\begin{array}{c}\text { 平均数 } \\
\text { 量 (只) } \\
\text { Means (ind.) }\end{array}$ & $\begin{array}{l}\text { 种类 (种) } \\
\text { Species } \\
\text { (Species) }\end{array}$ & $\begin{array}{l}\text { 数量（只） } \\
\text { No. (ind.) }\end{array}$ & $\begin{array}{c}\text { 种类 (种) } \\
\text { Species } \\
\text { (Species) }\end{array}$ \\
\hline 早期 Early stage & 13 & 330 & 66 & 22 & 44 & 42 & 5263 & 73 \\
\hline 中期 Middle stage & 17 & 27 & 61 & 22 & 37 & 69 & 1268 & 86 \\
\hline 晚期 Late stage & 20 & 39 & 67 & 23 & 27 & 52 & 1412 & 83 \\
\hline
\end{tabular}


表 42007 和 2008 年哀牢山金山Y口秋季各时期夜间网捕鸟类多样性测度指数

Tab. 4 Diversity index of birds captured at night at Jinshan yakou of Ailao Mountain in every stage during autumn 2007 and 2008

\begin{tabular}{|c|c|c|c|c|c|c|c|c|c|}
\hline \multirow{3}{*}{ 时期 Stage } & \multicolumn{3}{|c|}{2007 年 } & & \multicolumn{2}{|c|}{2008 年 } & \multicolumn{3}{|c|}{ 合计 Total } \\
\hline & 多样性 & 均匀度 & 优势度 & 多样性 & 均匀度 & 优势度 & 多样性 & 均匀度 & 优势度 \\
\hline & 指数 $H^{\prime}$ & 指数 J & 指数 $C$ & 指数 $H^{\prime}$ & 指数 $J$ & 指数 $C$ & 指数 $H^{\prime}$ & 指数 $J$ & 指数 $C$ \\
\hline 早期 Early stage & 1.48824 & 0.35522 & 0.48408 & 2.09508 & 0.52522 & 0.27782 & 1.63808 & 0.37825 & 0.43832 \\
\hline 中期 Middle stage & 3.39558 & 0.82600 & 0.05205 & 3.16495 & 0.76686 & 0.07327 & 3.38212 & 0.79608 & 0.05609 \\
\hline 晚期 Late stage & 3.24269 & 0.77121 & 0.06294 & 2.70932 & 0.6792 & 0.14043 & 3.20982 & 0.7325 & 0.07823 \\
\hline
\end{tabular}

喉歌鸲、黄脚三趾敦(Turnix tanki); 中期数量达到 高峰期的鸟类主要是夜路、灰头麦鸡 (Vanellus cinereus)、厚嘴苇茑。晚期开始迁飞的有黑胸冻 (Turdus dissimilis)、栗鸥(Emberiza rutila); 晚期数量 达到高峰的是红角鸮、红喉歌鸲、黄脚三趾塾、黑 胸冻、栗鸥。

\section{4 乌类组成随时段变化}

2008 年夜间不同时段间捕获数量和种类数量 相差较大，其中 20:00-22:00、02:00-04:00 和次 日凌晨 04:00-06:00 是夜间捕获鸟类数量的高峰时 段，平均每天捕获鸟类 7 只、 7 只和 9 只 $(n=67)$ 。 24:00-02:00 为捕获数量的低谷时段 (图 2), 平均 每天捕获鸟类 5 只 $(n=67)$ 。在 22:00-24:00 之间 平均每天捕获鸟类 6只。网捕种类除在 20:00-22:00 最低外, 其余时段高低变化与数量有相似。各个时 段网捕鸟类数量相差较大 (图 2), 但单因素方差分 析(One-way ANOVA)结果显示各时段网捕鸟类种 类和数量没有显著差异 $(F 4,104=0.137-0.571$, $P=0.684-0.968$ ）。

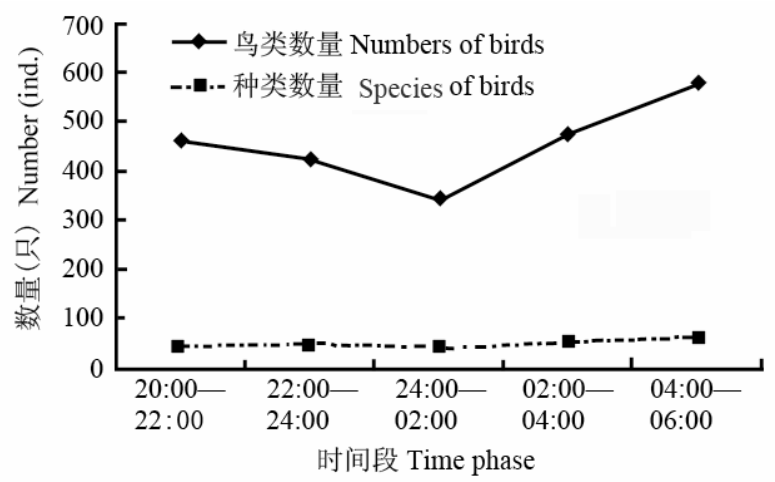

图 2 哀牢山金山Ү口夜间网捕鸟类种类和数量随 时段的变化

Fig. 2 Species and number changes with time phase birds captured at night at Jinshan yakou of Ailao Mountain

调查结果显示，小杜鹃、红尾伯劳、厚嘴苇茑、 红喉歌鸲、池鹭、蓝歌鸲、鹰鹃、红喉[姬]鹃、黑
胸鸫、红胸田鸡等整夜都有个体被捕获。小蝗莺 (Locustella certhiola)、山蓝仙鹃(Niltava banyumas)、 黑水鸡(Gallinula chloropus)等鸟类开始被捕获一般 在 22:00 以后; 黑枕黄丽鸟(Oriolus chinensis)、蚁烈 (Jynx torquilla)、小田鸡(Porzana pusilla)、橙头地鸫 (Zoothera citrine) 等鸟类夜间结束被捕获在凌晨 04:00 左右结束。小杜鹃、大杜鹃、红尾伯劳在 $20: 00$ - 22:00 网捕数量最多; 黑胸斩在 22:00-24:00 网捕数量最多; 池鹭和蓝歌鸲在凌晨 $02: 00-04: 00$ 网捕数量最多; 厚嘴苇莺、红喉歌鸲在凌晨 04:00-06:00 网捕数量最多。

\section{3 讨 论}

\section{1 两年鸟类多样性比较}

2007 年和 2008 年夜间在哀牢山金山Y口共网 捕到的鸟类有 129 种，7943 只。表明该地为鸟类夜 间迁徙活动的重要通道，再一次证明哀牢山金山Y 口是云南省的一个“打雀山” ( Wu \& Li，1999; Wang et al，2006; Wang \& Zhao，2009），也是开展鸟类 分类、环志和迁徙研究的重要地点, 对候鸟的保护 具有非常重要的保护价值。

两年期间夜间网捕鸟类种类和数量虽然均有 一定的变化, 但物种的组成变化明显小于数量变 化, 优势种基本不变, 只是在数量上发生了较大的 变化, 这与 1999 年帽儿山的调查结果 (Chang et al, 2001 ) 以及云南南涧凤凰山 2002 年与 2003 年的调 查结果（Huang et al，2006）相似。捕获鸟类中雀 形目鸟类较多，共 76 种，占 $58.9 \%$ ，这与云南哀牢 山鸟类迁徙的初步调查（Wei et al，1983）、云南隆 庆关秋季迁徙鸟类调查（Chu et al，1998）、新疆鸟 类环志调查（Ma et al，2004）、云南巍山鸟道雄关 夜间迁徙鸟类调查（Yang et al，2004）、北戴河林 栖鸟类调查（Zhong et al，2005）、云南南涧凤凰山 夜间鸟类多样性调查（Huang et al，2006）、云南鸟 类物种多样性现状 (Yang, 2009) 的研究结果相似。 
捕获鸟类中雀形目鸟类较多的原因可能有两点: 第 一, 小型鸣昺为了避免日间迁徙被捕的危险而采取 夜间迁徙的策略（Zheng，1995）; 第二, 小型鸣禽 的迁徙高度不超过 $300 \mathrm{~m}$, 而大型鸟类可以达到 3 000m 到 6300m (Zheng, 1995; Zhang \& Yang, 1997), 所以小型鸣禽很容易被网捕。

2007 年和 2008 年夜间网捕种类和数量分别为 114 种, 5229 只; 97 种, 2414 只。而 2004 年、2005 年和 2006 年 3 年期间总夜间网捕种类和数量, 分 别为 26 种, 129 只; 116 种, 3610 只; 125 种, 4452 只 (Zhang, 2009; Wang \& Zhao, 2009)。说明同 一地点, 不同年份夜间网捕鸟类数量及其种类存在 较大变动。这种变化可能与不同年份鸟类的繁殖情 况以及气候条件有关。但数量排在前 5 位的优势种 类, 几乎不变, 只有池鹭的位置发生了较小的改变。 说明每年飞经哀牢山金山Y口的优势种类变化不 大, 原因有两点: 第一, 这些优势种每年都按同一 条路线飞经哀牢山金山Y口; 第二, 每年飞经哀牢 山金山Y口的这些种类数量都较多。与候鸟迁徙路
线一般相对稳定（Zhang \& Yang，1997）的结果一 致。

2008 与 2007 年相比, 2008 年多样性指数、均 匀度指数、属间多样性指数都较高; 而优势度和科 间多样性指数以及 $G-F$ 指数都较低（表 2 ）。说明 2007 和 2008 年网捕鸟类在种、属和科 3 个分类等 级水平上的多样性以及网捕鸟类数量和优势种的 数量上都存在着一定的差异。根据红尾伯劳在 2007 年的数量猜测, 2008 年与 2007 年的上述差异, 主 要是由红尾伯劳的数量所占比例的变化引起的。故 剔除红尾伯劳, 再计算出这两年的多样性指数（表 5), 结果两年间的差异减小。这种变化与 Huang et al（2006）中提到雀形目鸟类的迁移鸟种类变动较 大, 从而引起两年间鸟类迁移动态变化较大的结果 相似。另一方面也与两年间不同的气候条件有关， 因为天气变化是影响夜间迁徙鸟类数量最关键的 因素 (Chu et al, 1998; Susanna et al, 2001; Han et al, 2007)。

\section{2 秋季各时期和夜间各时段鸟类组成分析}

表 5 剔除红尾伯劳后 2007 年与 2008 年秋季哀牢山金山Ү口夜间网捕鸟类多样性测度指数 Tab. 5 Diversity index of birds captured at night at Jinshan yakou of Ailao Mountain during autumn 2007 and 2008 without Brown Shrike (Lanius cristatus)

\begin{tabular}{|c|c|c|c|c|c|c|}
\hline 年份 Year & 数量 (只) No. (ind.) & 种类 (种) & Species (Species) & 多样性指数 $H^{\prime}$ & 均匀度指数 $J$ & 优势度指数 $C$ \\
\hline 2007 & 2536 & & 113 & 3.52731 & 0.74614 & 0.052696 \\
\hline 2008 & 1765 & & 96 & 3.39893 & 0.74467 & 0.058343 \\
\hline
\end{tabular}

对每天捕获鸟类的统计结果说明, 最多时每天 可捕捉 1643 只, 捕获种类最多的是 49 种, 捕获最 少的一天种类和数量都为 0 , 说明各天的捕捉数量 和种类变动非常显著。在整个观察期间, 早期网捕 鸟类数量最多, 但在南涧凤凰山数量最多的是在 9 月中旬一10 月上旬 (Han et al, 2007)。造成这两地 统计结果不一致的原因是哀牢山金山Y口早期红 尾伯劳较多, 1726 只, 占总网捕数量的 $21.7 \%$ 。中 期记录的种类则略多于早期和晚期 (表 3), 多样性 指数中期最高, 说明中期飞经哀牢山金山Ү口的鸟 类种类较多。这一结果与南涧风凰山在高峰期 (9 月中旬一 10 月上旬)鸟类种类最多 (Han et al, 2007) 相似。统计分析表明, 早、中、晚期数量和种类并 无显著差异, 这是因为各时期网捕鸟类种类和数量 均不一致, 在每个时期有些种类数量较少而另外一 些种类数量较多, 也就是说某些种类刚开始迁飞或 者迁飞即将结束, 而另一些种类数量正好在此时达 到高峰, 这种过程也是由于不同种类对迁徙应答的
不一致造成的。

早、中、晚期数量达到高峰的鸟类和云南南润 凤凰山、巍山隆庆关各时期的主要鸟类 (Chu et al, 1998; Han et al，2007）几乎一致。哀牢山每天夜 间 20:00-22:00和清晨 4:00-6:00捕获的鸟类种类 和数量较多, 这也与Han et al（2007）的夜间迁徙 高峰在 21:00-22:00和清晨 5:00相一致。每个时段被 捕获的优势种鸟类组成有差别, 表明每个时段迁飞 经过哀牢山金山Ү口的种类和数量都不同, 说明每 种夜间迁徙鸟在夜间迁徙时间不同, 印证了Victor \& Arseny（2006）提出的夜间迁徙鸟类飞行不仅可 以在夜幕刚降临时开始迁飞, 也可以在午夜开始迁 飞, 还可以在夜晚即将结束时开始迁飞的结论。从 本结果得到的整夜均有迁徙的种类与南润风凰山 整夜迁徙种类（池鹭、红喉姬鹟、鹰鹃等）(Han et al，2007）也几乎一致。

秋季各个时期、夜间时段鸟类种类和数量的差 异说明了各种夜间迁徙鸟类迁徙时间的不一致, 这 
一结果在较多研究中均有所体现 (Wei et al, 1983; Zhang, 1991; Li et al, 1999; Peter et al, 2005; Huang et al，2006; Victor \& Arseny，2006）。说明 鸟类迁徙时间是由外界环境气候因素和自身的内 源因素决定（Peter et al，2005; Victor \& Arseny， 2006）。

\section{3 不同 “打雀山” 秋季夜间迁徙鸟比较}

比较近几年云南省“打雀山”的研究结果, 哀牢 山金山Y口平均夜间网捕鸟类数量为 68 只 $(n=117)$, 凤凰山为 53 只 $(n=127)$ (Huang et al, $2006)$, 巍山为 156 只 $(n=36)$ (Yang et al, 2004)。 但捕获种类却是风凰山最多, 共 176 种 (Huang et al, 2006)。比较每天平均网捕鸟类种类和数量, 巍山 较其他两者高。这可能与巍山处于哀牢山金山Y口 和凤凰山的上端的地理位置有关。

哀牢山金山Ү口多样性指数和均匀度指数以 及属间多样性低于南涧风凰山, 而优势度指数却高 于凤凰山, 主要原因是哀牢山网捕鸟类数量最多的 是红尾伯劳, 所占的比例几乎接近总网捕数量的一 半, 在南涧风凰山红尾伯劳并不突出 (表 6)。而哀 牢山夜间网捕鸟类科间多样性低于南涧风凰山的 主要原因可能与哀牢山网捕鸟类种间数量不均匀 有关。
哀牢山金山Ү口和巍山以及凤凰山网捕优势 种类差别不大 (表 7), 主要原因是地理位置, 巍山 和哀牢山同属哀牢山山系, 而南润凤凰山虽属无量 山山系, 但与哀牢山几乎平行, 而且距离较近。因 此, 迁徙鸟类的组成也较为一致, 这也说明了三个 “打雀山”的迁徙鸟类都来自同一条迁徙通道。但是 各地夜间网捕的优势种所占百分比相差较大, 巍山 和凤凰山都是红喉[姬]能数量优先, 而哀牢山网捕 鸟类数量最多的是红尾伯劳, 所占的比例几乎接近 总网捕数量的一半，在南涧风凰山和巍山红尾伯劳 并不突出，这种差异的可能是地理和天气两种因素 共同影响形成。

针对哀牢山金山Y口夜间网捕鸟类多样性丰 富, 提出以下两点建议: 第一, 加大环志力度, 以 便拥有该地更多的鸟类组成数据; 第二，加强对周 围村民保护鸟类的教育宣传。

致谢：此次野外工作得到了云南省哀牢山自然 保护区新平管理局的李国松、杨宏、施文安、李勇、 白绍斌、王家和、罗田发等同志无私的帮助, 在此 致以诚挚的谢意！感谢鸟类组师兄吴飞对野外工作 的帮助, 感谢师兄伍和启、刘强、孔德军、王凯在 数据处理和论文修改方面给予的建议。

表 6 哀牢山和凤凰山的多样性测度表

Tab. 6 Diversity index of birds captured at night in Ailao Mountain and Fenghuang Mountain

\begin{tabular}{|c|c|c|c|c|c|c|}
\hline 打雀点 Bird migration localities & 多样性指数 $H^{\prime}$ & 均匀度指数 $J$ & 优势度指数 $C$ & 属间多样性指数 $G$ & 科间多样性指数 $F$ & $G-F$ 指数 \\
\hline 哀牢山 Ailao Mountain & 2.61 & 0.291 & 0.225 & 2.50 & 8.73 & 0.714 \\
\hline 凤凰山 Fenghuang Mountain & 3.89 & 0.752 & 0.036 & 4.13 & 25.56 & 0.838 \\
\hline
\end{tabular}

凤凰山有关数据来自 Huang et al (2006)。

Date of Fenghuang Mountain come from Huang et al (2006)

表 7 云南三大 “打雀点” 优势种鸟类所占百分比 (\%)

Tab. 7 Percent of dominant species in three major localities of bird migration in Yunnan

\begin{tabular}{|c|c|c|c|c|c|c|c|c|}
\hline \multirow{3}{*}{$\begin{array}{c}\text { 打雀点 } \\
\text { Birds migration } \\
\text { localities }\end{array}$} & \multicolumn{8}{|c|}{ 优势种鸟类所占比例 Percent of dominant species (\%) } \\
\hline & 红尾伯劳 & 小杜鹃 & 红喉歌鸲 & 厚嘴苇莺 & 池鹭 & 蓝歌鸲 & 红喉[姬]暡 & 树翏 \\
\hline & $\begin{array}{c}\text { Lanius } \\
\text { cristatus }\end{array}$ & $\begin{array}{c}\text { Cuculus } \\
\text { poliocephalus } \\
\end{array}$ & $\begin{array}{l}\text { Luscinia } \\
\text { calliope }\end{array}$ & $\begin{array}{c}\text { Acrocephalus } \\
\text { aedon }\end{array}$ & $\begin{array}{l}\text { Ardeola } \\
\text { bacchus }\end{array}$ & $\begin{array}{c}\text { Luscinia } \\
\text { cyane }\end{array}$ & $\begin{array}{c}\text { Ficedula } \\
\text { parva }\end{array}$ & $\begin{array}{c}\text { Anthus } \\
\text { hodgsoni }\end{array}$ \\
\hline 哀牢山Ailao Mountain & 45.85 & 6.22 & 5.11 & 4.96 & 3.49 & 1.99 & 0.96 & 0.65 \\
\hline 凤凰山 Fenghuang Mountain ${ }^{\mathrm{a}}$ & 5.08 & 5.59 & 7.41 & 3.51 & 3.23 & 7.05 & 9.73 & 3.28 \\
\hline 巍山 Wei Mountain ${ }^{\text {b }}$ & 3.25 & 1.29 & 17.10 & 1.91 & 0.89 & 1.78 & 22.27 & 15.83 \\
\hline
\end{tabular}

a 凤凰山有关数据来自 Huang et al (2006); b 巍山有关数据来自 Yang et al (2004)。

a Date of Fenghuang Mountain come from Huang et al (2006); b Date of Wei Mountain come from Yang et al (2004).

\section{参考文献:}

Bruderer B, Liechti F. 1995. Variation in density and height distribution of nocturnal migration in the south of Israel [J]. Journal of Zoology, 41(3): 477-487.

Chang JC, Li JT, Shen XM. 2001. A study on bird banding in 1999 spring in
Maoershan, Heilongjiang Province[J]. Chinese Journal of Zoology, 36(3): 53-54. [常家传, 李俊涛, 沈晓明. 2001. 帽儿山1999 年春季 鸟类环志. 动物学杂志, 36(3): 53-54.]

Chu GZ, Wang ZJ, Kiyoaki O, Zhang X, Qian FW. 1998. Study on the bird 
banding in fall in Longqingguan, Yunnan Province [J]. sei silvae sin, 34(3): 66-73. [楚国忠, 王紫江, 尾崎清明, 张 旭, 钱法文. 1998. 云南隆庆关秋季鸟类环志研究. 林业科学, 34(3): 66-73.]

Han LX, Huang SL, Yuan YC, Qiu YL. 2007. Fall migration dynamics of birds on Fenghuang Mountains, Yunnan Province, China [J]. Zoo Res, 28 (1): 35-40. [ [ 韩联宪, 黄石林, 袁玉川, 邱云龙. 2007. 云南南涧 凤凰山秋季迁移鸟迁移时序与数量变化. 动物学研究, 28(1): 35-40.]

Huang SL. 2004. Study on Bird Migration in Fenghuang Mountains Nanjian County, Yunnan Province during Autumn Migration [D]. Master thesis, Southeast Forestry College, Kunming, Yunnan.

Huang SL, Hang LX, Gao SZ, Luo ZY. 2006. Analysis of migratory diversity of fall night in Fenghuang Mountains Nanjian County, Yunnan Province [J]. Zoo Res, 27(2): 163-168. [黄石林, 韩联宪, 高 素珍, 罗增阳. 2006. 云南南涧风凰山秋季夜间迁移鸟类多样性分 析. 动物学研究, 27(2): 163-168.]

Jiang AW, Zhou F, Wei ZH, Lu Z. 2006. A survey of photo tactic birds in "Daniaoao" of Damiao Mountains, Guangxi [J]. Chinese Journal of Zoology, 41(6): 129-133. [蒋爱伍, 周 放, 韦振海, 陆 舟. 2006. 广西大苗山 “打鸟坳”趋光性鸟类调查. 动物学杂志, 41(6): 129-133.]

Jiang ZG, Ji LQ. 1999. Avian-mammalian, species diversity in nine representative sites in China [J]. Biodiversity Sci, 7(3): 220-225. [蒋志 刚, 纪力强. 1999. 鸟兽物种多样性测度的G-F指数方法. 生物多样 性, 7(3): 220-225.]

Ma M, Leader PJ, Ying HK, Carey GJ. 2004. A report of bird banding in Xinjiang, China [J]. Arid Zone Research, 21(2): 183-186. [马 鸣, Leade P, 英克劲, Geoff Carey. 2004. 新疆鸟类环志简报. 干早区研 究, 21(2): 183-186.]

Peter PM, Charles MF, Robert SM, Frank RM. 2005. The influence of climate on the timing and rate of spring bird migration [J]. Oecologia, 142: 307-315.

Susanna Z, Susanne Å, Felix L, Bruno B. 2001. Nocturnal autumn bird migration at Falsterbo, South Sweden [J]. Journal of Avian Biology, 32: 239-248.

Tang W, Deng XJ, Wang B. 2003. Research on migratory birds via Daniaoao of Longhui County in Hunan [J]. Journal of Hunan Polytechnic of Environment and Biology, 9(2): 29-33. [汤 伟, 邓学 建, 王 斌. 2003. 湖南隆回打鸟坳迁徙鸟类资源的调查研究. 湖南 环境生物职业技术学院学报, 9(2): 29-33.]

Todd JM, Brian AC. 2004. Nocturnal bird migration in northeastern Oregon and southeastern Washington [J]. Northwestern Naturalist, 85(2): 39-47.

Victor NB, Arseny T. 2006. Timing of nocturnal autumn migratory departures in juvenile European robins (Erithacus rubecula) and endogenous and external factors [J]. Journal Ornithol, 147: 298-309.

Wang ZJ, Wu JL, Zhao XB, Yang M. 2006. A study on the nocturnal migrating birds in autumn [A]. In: Wang YC, Wang ZJ, Gao ZW, Yang L. Yunnan Proceeding of International Forum on Man and Birds in Harmony [M]. Kunming: Yunnan Science \& Technology, 166-182. [王紫江, 吴金亮, 赵雪冰, 杨 明. 2006. 云南秋季夜间迁徙鸟类 研究. 见: 王月冲, 王紫江, 高正文, 杨岗. 人鸟和谐国际论坛论文 集. 昆明: 云南科技出版社, 166-182.]

Wang ZJ, Zhao XB. 2009. The study on bird banding at birds captured mountain in Yunnan province [A]. In: Wang ZJ, Huang HK, Yang XJ.
Bird Conversation, Man and Birds in Harmony [M]. Beijing: China Forestry Publishing House, 118-126. [王紫江, 赵雪冰. 2009. 云南的 “打雀山”与鸟类环志问题研究. 见: 王紫江, 黄海魁, 杨晓君. 保护 鸟类, 人鸟和谐. 中国林业出版社, 118-126.]

Wei TH, Liu GZ, Shi WY, Ma SL. 1983. The primary study of bird-migration on Ailao Mountains [A]. In: Laboratory of Ecology Kunming Branch, Academia Sinica. Research of Forest Ecosystem in Ailao Mountains, Yunnan [M]. Yunnan Science and Technology Press, 297-313. [魏天吴, 刘光佐, 石文英, 马世来. 1983. 哀牢山鸟类迁徙 的初步研究. 见: 云南哀牢山森林生态系统研究. 中国科学院昆明 分院生态研究室. 云南科技出版社, 297-313.]

Wei TH, Wang ZJ, Cui QY. 1988. The birds in northern and middle parts of the Ailao Mountains [A]. In: Comprehensive Survey Group of the Ailao Mountains Natural Reserve. Comprehensive Survey Collection of the Ailao Mountains Natural Reserve [M]. Yunnan: Yunnan National Publishing House, 206-230. [魏天吴, 王直军, 崔庆余. 1988. 哀牢山 中北段的鸟类. 见: 哀牢山自然保护区综合考察团. 哀牢山自然保 护区综合考察报告集. 云南: 云南民族出版社, 206-230.]

Wu JL, Li ZQ. 1999. Survey on localities of bird capturing in Yunnan [J]. Journal of Yunnan University, 21(2): 106-108. [吴京亮, 李宗强. 1999. 云南“打雀点”的调查研究. 云南大学学报, 21(2): 106-108.]

Xiao FZ, Li MJ, Jiang Y. 2005. The study of migratory birds passage in Suichuan [J]. Jiangxi Forestry Science and Technology, 3: 8-10. [肖放 珍, 李茂军, 蒋 勇. 1999. 遂川候鸟通道研究. 江西林业科, 3: 8-10.]

Yang XJ. 2009. An analysis of present situation of birds diversity in Yunnan [A]. In: Wang ZJ, Huang HK, Yang XJ. Bird Conversation, Man and Birds in Harmony [M]. Beijing: China Forestry Publishing House, 1-45. [杨晓君. 2009. 云南鸟类物种多样性现状. 见: 王紫江, 黄海 魁, 杨晓君. 保护鸟类, 人鸟和谐. 中国林业出版社, 1-45.]

Yang Y, Wang ZJ, Zhao ZJ, Ma SL. 2004. Research on bird ringing in Niaodaoxiongguan, Weishan County, Yunnan in 2003[J]. Sichuan Journal of Zoology, 23(2): 120-122. 杨 荣, 王紫江, 赵正军, 马赛 龙. 2004. 云南巍山鸟道雄关2003年度鸟类环志研究简报. 四川动 物, 23(2): 120-122.]

Zhang FQ. 1991. The survey of birds of migration in Tanghai County [J]. Journal of Hebei Normal University, 3: 58-65. [张福群. 1991. 唐海县 迁徙鸟类的调查. 河北师范大学学报, 3: 58-65.]

Zhang FY, Yang RL. 1997. Bird Migration Research of China [M]. Beijing: China Forestry Publishing House. [张孚允，杨若莉. 1997. 中国鸟类 迁移研究. 中国林业出版社.]

Zhang HY. 2009. A primary research of the birds banding on Xinping Jinshan Yakou of Ailao Mountains Nature Reserve at night [A]. In: Wang ZJ, Huang HK, Yang XJ. Bird conversation, Man and Birds in Harmony [M]. Beijing: China Forestry Publishing House, 136-140.[张 宏雨. 2009. 哀牢山自然保护区新平金山Y口夜间鸟类环志初探. 见: 王紫江, 黄海魁, 杨晓君. 保护鸟类, 人鸟和谐. 中国林业出版 社, 136-140.]

Zheng GM. 1995. Ornithology [M]. Beijing: Beijing Normal University Press. [郑光美. 1995. 鸟类学. 北京: 北京师范大学出版社.]

Zhong Y, Yang JG, Liu YH, Yu P. 2005. The Banding Research of Wood Migratory Bird at Beidaihe in 2002 [J]. Chinese Journal of Zoology, 40(2): 90-95. [钟 义, 杨金光, 刘永红, 于 萍. 2005. 2002年北戴 河林栖迁徙鸟类环志. 动物学杂志, 40(2): 90-95.] 